\title{
COST OF DYSPEPSIA AND GASTROESOPHAGEAL REFLUX DISEASE IN BANGLADESH
}

AFTAB H ${ }^{1}$, BEGUM HA ${ }^{2}$, RAHMAN $\mathrm{M}^{3}$

\begin{abstract}
Objectives: To estimate the cost of dyspepsia and gastro-oesophageal reflux disease in Bangladeshi patient

Methods: A consecutive sample of fifty nine patients attended outpatient clinic of Gastroenterology department of Dhaka Medical College Hospital (June to July 2008) were evaluated using an interview-assisted questionnaires for gastro-oesophageal reflux disease (i.e. heartburn or regurgitation on a weekly basis for at least the past 3 months, and symptom onset at least 12 months prior to the study) or dyspepsia symptom(based on Rome II criteria). The frequency of health resource utilization (i.e. physician visit, hospitalization, laboratory tests, instrumental studies, and medications) and productivity loss (days off work) due to gastro-oesophageal reflux disease or dyspepsia-related symptoms in the past 12 months were recorded. Societal perspective was used, and cost of illness per person per year was estimated in purchasing power parity dollars (PPP\$).
\end{abstract}

Results: The cost of illness per person per year for patients with gastro-oesophageal reflux disease, and dyspepsia alone were around PPP\$33.29 and PPP\$55.35, respectively. There was no statistically significant difference in the cost of illness between the two groups. The direct costs of disease comprised 91.49\%and 93.02\%of the total costs in gastro-oesophageal reflux disease and dyspepsia patients, respectively with the costs of medications being the dominant component for dyspepsia and investigation cost for gastro-oesophageal reflux disease.

Conclusion: Gastro-oesophageal reflux disease and dyspepsia, contribute substantially to the direct costs of medical care in a developing country like Bangladesh.

Keywords: Dyspepsia, gastro-oesophageal reflux disease, cost of treatment.

J Dhaka Med Coll. 2009; 18(2) : 101-104

\section{Introduction:}

Both dyspepsia and GORD imposes great economic burden on society. In 1991 Nyer estimated that just for those with functional dyspepsia consulting a physician, the annual direct cost to Swedish economy was US\$91 million, the indirect cost was US\$852 million ${ }^{1}$. Similarly, GORD is nowadays the disease with the highest direct cost in USA 19.3 billion US dollar) ..$^{2}$ Dyspepsia and GERD are highly focused research interest in the Western country. It is assumed that there will be great difference between the prevalence rate,its pattern and impact of both dyspepsia and GORD in developing country like Bangladesh due to different socio-cultural background. A study conducted on defined population in the year 1985 reported $41 \%$ point prevalence of peptic ulcer dyspepsia ${ }^{3}$. Dyspepsia and GORD would not be so important if it was not associated with reduction of quality of life and considerable financial burden ${ }^{4-9}$. Investigations and treatments for dyspepsia and GORD continue to become more sophisticated and expensive. Country has limited resources and healthcare decisions makers are increasingly under pressure to contain costs. The objective of this study was to estimate the cost of dyspepsia and GORD among Bangladeshi population.

\section{Patients and Methods:}

This cross-sectional study was conducted in the outdoor clinic of Gastroenterology department of Dhaka Medical College Hospital. Total study duration was eight week (June to July 2008).A

1. Department of Gastroenterology, Dhaka Medical College, Dhaka.

2. Institute of Health Economics, University of Dhaka, Dhaka.

3. Institute of Epidemiology, Disease Control and Research, Dhaka.

Correspondence : Dr. H Aftab 
purposive sampling technique was followed for the recruitment in the study during data collection period. Data was colleted anonymously via face to face interview using a questionnaire. An informed consent was signed by both interviewer and participant. This study was approved by the institutional ethical review committee.

\section{Development of questionnaire}

A questionnaire was developed following thorough literature review and internationally validated questionnaire considering our sociocultural background.

\section{Operational Definition:}

Dyspepsia was defined based on Rome II criteria as pain or discomfort centered in the upper abdomen for at least 12 weeks which need not be consecutive within the preceding 12 months, and no evidence indicates that it is exclusively relieved by defecation or associated with the onset of a change in stool frequency or stool form ( (i.e. not irritable bowel syndrome) ${ }^{10}$.

Gastro esophageal reflux disease: Heartburn or regurgitation on a weekly basis for the past 3 months.

Onset of both dyspepsia and GORD must be at least 12 months prior to the study.

\section{Cost analysis}

The costs were analyzed from the societal perspective. All costs were converted to PPP\$ (purchasing power parity dollars) to facilitate cross country comparison of the costs. The unit costs of health resources including physician visits, laboratory tests and drugs were calculated from the patient's statement. As most of the patients did not know the exact amount of the expenditure they had in the last one year, we considered the minimum cost unless the patient exactly knew. Productivity loss was measured by the number of the days on which GORD or dyspepsia-related symptoms had completely interfered with patient's daily activities. The patients reported the number of the days they had been absent from their job due to their symptoms during the past 12 months. The average daily income of individual assumed to be 1/365 of GNI (gross national income) per capita.

GNI per capita in US \$ and PPP was retrieved from World Bank website (in 2007).

Data analysis: It was done by SPSS11.5 version. Chi-square test and Mann-Whitney U tests were employed. $P$-values below 0.05 were considered significant.

\section{Result:}

Twice weekly Gastroenterology department of Dhaka Medical College render outpatient service for referral patients. During three weeks data collection period total 175 patients attended the outdoor, fifty nine patients were enrolled in this study. Among them 26(44.1\%) were male and 33(59.9\%) were female, mean \pm S.D of age: $33.7 \pm 9.9$ years. Gastro esophageal reflux disease (GORD) alone was found in twenty nine $(49.2 \%)$ patients, rest of them (50\%) had complaints of dyspepsia. Type of consultation before coming to this hospital is shown in Table I. There was no history of hospitalization due to this illness. Both groups had consultation with MBBS doctor and preferably used to take drugs from pharmacy shop. Patients with abdominal pain did follow the prescription whereas GORD were used to take self medication (Table 1I). Most of the patients in both groups used Proton Pump Inhibitors (PPI) for their treatment (Fig.-I \& Fig.II). The costs of illness per person per year for dyspepsia and GORD are shown in the table III There was no statistically significant difference in total direct cost of disease per patient per year, or in the frequency of use of different health service categories. The mean \pm SD of the days off work was $3.3 \pm 7.5$, and $2.2 \pm 4.5$ days among dyspepsia and GORD patients respectively in the past one year. The difference between the frequencies of days off work between the two groups was not statistically significant. 
Table-I

Type of consultation between two disease group

\begin{tabular}{lcc}
\hline Type of consultation & $\begin{array}{c}\text { Dyspepsia } \\
(\mathrm{n}=30)\end{array}$ & $\begin{array}{c}\text { Gord } \\
(\mathrm{n}=29)\end{array}$ \\
\hline MBBS & $13(41.9 \%)$ & $18(58.1 \%)$ \\
Homeopath & $6(27.3 \%)$ & $16(72.7 \%)$ \\
Specialist doctor & $1(14.3 \%)$ & $6(85.7 \%)$ \\
Village doctor & $9(50 \%)$ & $9(50 \%)$ \\
Medicine shop & $13(46.4 \%)$ & $15(53.6 \%)$ \\
Traditional healer & $3(25 \%)$ & $9(75 \%)$ \\
Government hospital & $9(56.3 \%)$ & $7(43.8 \%)$ \\
Private clinic & $5(55.6 \%)$ & $4(44.4 \%)$ \\
Other hospital & 0 & $4(100.0 \%)$ \\
\hline
\end{tabular}

Table-II

Pattern of drug consumption

\begin{tabular}{lcc}
\hline Pattern of medication & $\begin{array}{c}\text { Dyspepsia } \\
(\mathrm{n}=30)\end{array}$ & $\begin{array}{c}\text { Gord } \\
(\mathrm{n}=29)\end{array}$ \\
\hline Self medication & & \\
$\quad$ yes & $8(34.8 \%)$ & $15(65.2 \%)$ \\
no & $19(59.4 \%)$ & $13(40.6 \%)$ \\
\hline
\end{tabular}

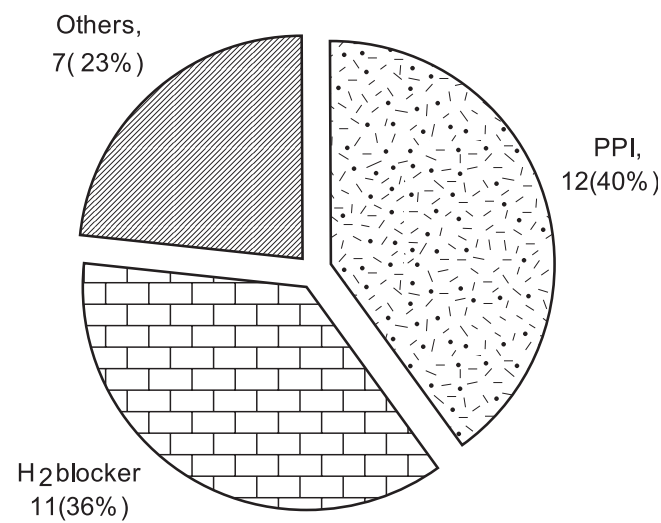

Fig.-1: Type of drugs use in dyspepsia

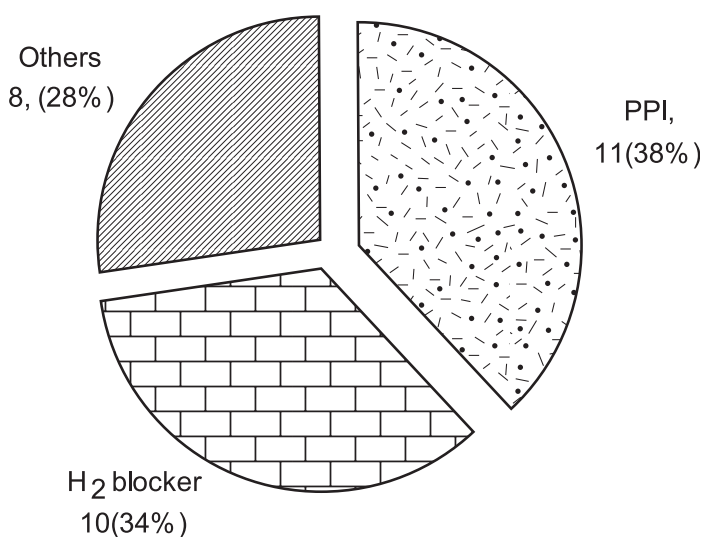

Fig.-2: Type of drugs use in gord.

Table-III

Cost of disease per person per year among patients with dyspepsia( $n=30)$ and GORD $(n=29)$ in a 12 month period

\begin{tabular}{lcccccc}
\hline Cost & \multicolumn{3}{c}{ Dyspepsia } & \multicolumn{3}{c}{ GORD } \\
& Taka & PPP\$ & $\%$ & Taka & PPP\$ & $\%$ \\
\hline Drug & 707.79 & 29.86 & 53.94 & 474 & 20 & 6 \\
Investigation & 366.18 & 15.45 & 27.91 & 399.18 & 16.84 & 50.58 \\
Others & 144.25 & 6.08 & 10.98 & 61.43 & 2.59 & 7.78 \\
Total direct & 1220.40 & 51.49 & 93.02 & 722 & 30.46 & 91.49 \\
Total indirect & & 3.86 & 6.97 & & 2.83 & 8.50 \\
\hline Total cost & & 55.35 & 100 & & 33.29 & 100 \\
\hline
\end{tabular}

$\dagger$ PPP\$: purchasing power parity dollar or international dollar which was estimated to be equal to 23.7 taka by comparing 2007 GNI percapita in US dollars (470 \$) and PPP(1340 PPP\$) from World Bankdatabase (and the exchange rate of 1 US\$ $=68.59$ taka in 2009)

\section{Discussion:}

This cross sectional study estimated the direct and indirect cost of dyspepsia and GORD among patients referred to Gastroenterology outpatient department in Dhaka Medical College Hospital. In this study, the total costs of GORD and dyspepsia were PPP\$33.29 and PPP \$55.35 respectively. This cost estimation differs from other countries. Willich et al. studied a population from three European countries, and reported the direct cost of GORD per person per year to be about $342^{11}$. A Swedish study reported the total cost of GORD or dyspepsia per person per year to be US\$63 ${ }^{6}$.It seems that the costs of 
GORD or dyspepsia found in most European population-based studies which surveyed general population are higher than that in our study. This might be due to the lower price of health services such as lower costs of physician visit, and domestic pharmaceutical products in Bangladesh compared with that in European countries. The other explanation for our lower estimations might be the minimalist approach we took in unit cost estimation. For example, we took into account the costs applied in public health centre which are relatively lower than that in private sector. In addition, we assumed that the patients had used the cheapest brand of drugs in the market. Bangladesh health administration system still lacks an integrated digital health information system for medical records, and in this study, the calculation of costs (i.e. frequency of health care use) had to be based on questionnaires and patients' recall, but not patients' medical records. Especially with regard to medications, patients' self-reports might not be accurate and could be subject to recall bias. The medication cost accounted for over $50 \%$ in case of dyspepsia whereas investigation cost was dominant in GORD. It might be due to most bothersome symptoms in GORD justifying their investigations and self medication reducing the frequency of drug consumption. Proton-pump inhibitors, H2blockers, and antacids were the most common medications used by the patients and contributed to the largest proportion of medication costs. Dhaka medical college is a tertiary care hospital in Bangladesh. Before coming to this hospital, patients were mostly used to consult with MBBS doctor and nearest medicine shop. Homeopathy was found popular among GORD. Consultation with specialist doctor was less in both groups due to higher fees charged by specialist.

Besides the direct cost of medical care, these diseases lead to reduction in work productivity. This productivity reduction can seem to take many forms: time off for medical care, days missed because of illness, reduced productivity at times the person is on the job, reduction of the number of hours scheduled for work (changing from full time to part-time work), and complete disability. The mean of the number of the days per year the patients were absent form works due to dyspepsia or GORD symptoms ranged between 3.3 to 2.2 in this study which was higher to that found by other studies. ${ }^{11,7}$.
This might be explained by the fact that this study involved more severe cases of disease associated with higher productivity loss.

\section{Conclusion:}

The impact of GORD and dyspepsia on the economy differs widely from country to country depending on several factors (like cultural, socioeconomic, and economical status). Nevertheless, this study suggests that direct costs are higher than indirect costs for both group of patients with dyspepsia and GORD in Bangladesh. A population-based study is needed to have a more precise estimation of cost of GORD and dyspepsia.

\section{References:}

1. Drossman DA, Li SA Andruzzi E, Temple RD, Tolley NJ, Thompson, et al. US householder survey of functional gastrointestinal disorders. Dig Dis Sci 1993; 38: 1569-80.

2. Sandler R S, Ecerhart J E, Donowitz M,Adams $\mathrm{E}$, et al. The burden of selected digestive diseases in the United States. Gastroenterology 2002; 122: 1500-11.

3. Khan AKA, Hasan M, Roy PK, Aziz S, Haq KM, Ali SMK, et al. Peptic ulcer in Bangladesh. BMRC Bull, 1987; XIII(1): 29-72.

4. Joish VN, Donaldson G, StockdaleW, Oderda GM, Crawley J, SasaneR, et al. The economic impact of GERD and PUD: examination of direct and indirect costs using a large integrated employer claims database. Curr Med Res Opin 2005;21:535-44.

5. Kurata JH, Nogawa AN, Everhart JE. A prospective study of dyspepsia in primary care. Dig Dis Sci 2002;47:797-803.

6. Agreus L, Borgquist L. The cost of gastrooesophageal reflux disease, dyspepsia and peptic ulcer disease in Sweden. Pharmacoeconomics 2002; 20: 347-55.

7. Leodolter A, Nocon M, Kulig M,Willich SN, Malfertheiner P, LabenzJ. Gastro esophageal reflux disease is associated with absence from work: results from a prospective cohort study. World JGastroenterol2005; 11:7148-51.

8. Stanghellini V, Cogliandro R, Cogliandro L, De Giorgio R, BarbaraG, Corinaldesi R. Unsolved problems in the management of patients with gastro-oesophageal reflux disease. Dig Liver Dis 2003; 35: 843-8.

9. Meineche-Schmidt V, Jorgensen T. Fluctuation in dyspepsia subgroups over time. three-year follow-up of patients consulting general practice for dyspepsia. Dig Liver Dis 2002; 34: 332-8.

10. Talley NJ, Stanghellini V, Heading RC, Koch KL, Malagelada JR,Tytgat GN. Functional gastro duodenal disorders. Gut 1999; 45(Suppl.2): II37-42.

11. Willich SN, Nocon M,Kulig M, Jaspersen D, Labenz J,Meyer-Sabellek W, et al. Cost-of-disease analysis in patients with gastro-oesophageal reflux disease and Barrett's mucosa. Aliment Pharmacol Ther 2006; 23: 371-6. 